\title{
Nunca más. Elementos para no repetir el conflicto armado en Colombia
}

\author{
Never again. \\ Elements to avoit repeating the armed conflict in Colombia
}

DOI: http://dx.doi.org/10.17981/cultedusoc.10.2.2019.07

Recibido: 12/01/2018 Aceptado: 28/09/2018

Julián Andrés Escobar Gómez

LCN- Idiomas- Medellín (Colombia)

elprofeta91@gmail.com

Para citar este artículo:

Escobar, J. (2019). Nunca más. Elementos para no repetir el conflicto armado en Colombia. Cultura, Educación y Sociedad, 10(2). 8596. DOI: http://dx.doi.org/10.17981/cultedusoc.10.2.2019.06

\section{Resumen}

El objetivo principal de este artículo es develar la preocupación de No-Repetir el conflicto armado en Colombia expresado en el Acuerdo Final de paz entre el Gobierno Nacional de Colombia y las Fuerzas Armadas Revolucionarias de Colombia-Ejército del Pueblo (FARC-EP). Se toma como unidad de estudio las dos versiones del acuerdo, publicados el 24 de agosto del 2016 (antes del plebiscito por la paz) y el 24 de noviembre del 2016 (posterior al plebiscito y cuentan con las concertaciones de los opositores). En lo metodológico se aplica la técnica del análisis de contenido fundamentado en procesos reflexivos y argumentativos. El resultado destaca como en ambas versiones hay una intencionalidad muy clara de no repetir el conflicto armado en Colombia. Se concluye en la tesis de No-Repetir el conflicto armado significa eliminar todas las condiciones de posibilidad que lo originaron y lo perpetuaron durante tanto tiempo. Dicho de otro modo: no repetirlo es superarlo.

Palabras clave: Acuerdo Final; No-Repetición; superación del conflicto armado; proceso de paz

\section{Abstract}

The main objective of this article is to unveil the concern of Non-Repeating the Armed Conflict in Colombia expressed in the Final Peace Agreement between the National Government of Colombia and the Revolutionary Armed Forces of Colombia-People's Army (FARC$\mathrm{EP})$. The two versions of the agreement, published on August 24, 2016 (before the peace plebiscite) and November 24, 2016 (after the plebiscite and with the agreement of the opponents), are taken as the unit of study. In terms of methodology, the technique of content analysis based on reflexive and argumentative processes is applied. The result highlights how in both versions there is a very clear intention not to repeat the armed conflict in Colombia. The thesis of Non-Repeating the Armed Conflict concludes that eliminating all the conditions of possibility that originated it and perpetuated it for so long. In other words, not to repeat it is to overcome it.

Keywords: Final Agreement; Non-Repetition; overcoming the armed conflict; peace process 


\section{INTRODUCCIÓN}

En el presente artículo se presenta un análisis de los acuerdos de Paz alcanzados entre el Gobierno Nacional de Colombia y las Farc-Ep ${ }^{1}$. La intención principal es es develar la preocupación de No-Repetir el conflicto armado en el país. La tesis argumentativa refiere que para superar el conflicto armado se debe eliminar todas y cada una de las causas que lo originaron, pues, de lo contrario, la posibilidad real de repetirlo estará siempre latente en la sociedad. El mismo hecho se menciona en reiteradas ocasiones a lo largo del Acuerdo Final publicado en dos versiones: la primera el 24 de agosto de 2016, fecha previa a la realización del llamado plebiscito por la paz; y la segunda data del 24 de noviembre del 2016, fecha posterior al plebiscito y que contiene las concertaciones con el grupo de opositores que, a la cabeza del expresidente Álvaro Uribe Vélez, llevaron a cabo la campaña por el no en este proceso electoral.

Se encuentra que no hay una diferencia evidente en ambas versiones del Acuerdo Final en términos de la superación del conflicto armado como el deseo de no volver a repetirlo. En ambas versiones se explícita el tema que es al mismo tiempo un anhelo y un objetivo al que apunta lo construido en la Habana y presentado en la ciudad de Cartagena.

Lejos de cualquier posición o disputa por un partido político, el momento histórico en el cual se encuentran los colombianos es

\footnotetext{
${ }^{1}$ Para las personas que han leído el texto completo del Acuerdo Final sabrán que este título es el que le será otorgado al informe de la Comisión de Verdad, Justicia, Reparación y No Repetición. El autor ha decidido poner el mismo título diferenciándolo del informe con un subtítulo, porque aquí se pretende mostrar algunas nociones de lo que hipotéticamente será el objetivo principal de los colombianos en los próximos años y el de la comisión en su texto que será presentado en el momento oportuno: que el conflicto armado en Colombia No se repita
}

decisivo para pensar una identidad nacional diferente y en donde podrán construir un proyecto como República para que, en un futuro tal vez no tan lejano, puedan tener una imagen de una nación distinta a lo que se tiene hoy. Y, en cierto modo, los colombianos podrán liberarse del miedo con el cual han vivido los pasados 60 años de un conflicto armado que solo le ha traído dificultades al país. Se argumenta también que el hecho de no-repetir el conflicto armado conlleva a pensar en la construcción de un destino y una identidad diferente. Todo ello se desprende del estudio que se realiza del Acuerdo Final. Para las citaciones en este artículo se ubica en primer lugar aquellas que corresponden a la versión del acuerdo concertada con los opositores y entre corchetes la presentada en Cartagena en el mes de agosto del 2016.

\section{No repetir el conflicto armado}

Se plantea de forma reiterada el deseo manifiesto de las Farc-Ep y del Gobierno Nacional de no repetir el conflicto armado ${ }^{2}$ en Colombia ${ }^{3}$. Esto se evidencia dentro del Acuerdo Final ${ }^{4}$ (2016), tal como se expresa:

\footnotetext{
${ }^{2}$ Iniciamos este apartado con el llamado de atención que ya se ha hecho en otro artículo publicado en el 2016 cuyo título es: Educar para no repetir el conflicto armado. El autor realiza allí un llamado preliminar acerca del no repetir los hechos de violencia que han marcado la historia reciente de Colombia, aunque lo hace desde una perspectiva estrictamente educativa. Cabe aclarar que ese artículo fue publicado sin haberse firmado el Acuerdo Final en la ciudad de Cartagena. Sin embargo, es necesario advertir la importancia de ese concepto de no repetición incluso antes de la aparición de ese importante Acuerdo que seguro ha marcado un punto en la historia de los colombianos.

${ }^{3}$ Junto con los autores del texto titulado Las garantías de no repetición como mecanismo para la obtención de la paz, cuya referencia completa se encuentra en la bibliografía, concordamos con que la no repetición es la garantía básica para alcanzar una paz estable y duradera, lo cual es objetivo principal del Acuerdo Final presentado en la ciudad de Cartagena. Agradecemos la revisión de todos los textos aquí referenciados.

${ }^{4}$ El nombre completo del documento es: Acuerdo Final para la Terminación del Conflicto y la Construcción de una Paz Estable y Duradera. De ahora en adelante se nombrara simplemente como Acuerdo Final.
} 
Poniendo en consideración que la suma de los acuerdos que forman el Acuerdo Final contribuyen a la satisfacción de derechos fundamentales como son derechos políticos, sociales, económicos y culturales; los derechos de las víctimas del conflicto a la verdad, la justicia y la reparación; el derecho de los niños, niñas y adolescentes, el derecho fundamental de la seguridad jurídica individual y/o colectiva y la seguridad física y el derecho fundamental de cada individuo [en particular] y de la sociedad [sin distingos en generall a la no repetición de la tragedia del conflicto armado interno que con el presente Acuerdo se propone superar definitivamente (p. 2 [p. 2]).

Igualmente el Acuerdo $^{5}$ (2016) con las Farc-Ep ${ }^{6}$ dicta:

El Gobierno Nacional y las Farc-Ep comparten el propósito de que se reviertan los efectos del conflicto, que se restituyan las víctimas del despojo y del desplazamiento forzado y a las comunidades sus derechos sobre la tierra, y que se produzca el retorno voluntario de mujeres y hombres en situación de desplazamiento (p. 17 [p. 14]).

En función de lo referido se argumenta en primer lugar que, la no-repetición del conflicto armado en Colombia se plantea aquí como un derecho de todos los ciudadanos, especialmente de aquellos que han debido soportar con mayor intensidad los efectos del conflicto [armado interno], y este debe ser restituido después de más de 60 años de intranquilidad. En segundo lugar, uno

\footnotetext{
${ }^{5}$ Como se dijo en la introducción, la página que no está entre corchetes corresponde a la versión del Acuerdo Final del mes de noviembre del 2016, y la que está dentro de ellos es la presentada en la ciudad de Cartagena en el mes de agosto. Ambas versiones del Acuerdo Final están disponibles en internet para su descarga gratuita.

${ }^{6}$ Estas son las siglas para: Fuerzas Armadas Revolucionarias de Colombia - Ejército del Pueblo. Es el grupo guerrillero más antiguo de Colombia iniciado, en un primer momento, como un movimiento campesino que buscaba el mejoramiento del campo en esta nación, entre algunas otras cuestiones.
}

de los objetivos del Acuerdo Final es «superar definitivamente» el conflicto armado en esta nación, lo cual deja a la población ad portas del pensamiento de que para poder superarlo es necesario no volver a repetirlo. Dicho de otro modo: la no-repetición es un objetivo (un derecho al que todos deben tener acceso), un destino al cual deben apuntar, pero al mismo tiempo es un camino para llegar al futuro deseado. Y esto es un propósito en común entre el Gobierno Nacional y las Farc-Ep.

Como se observa, los propósitos o el alcance que corresponde al Acuerdo Final ${ }^{7}$ es bastante complejo, pues no solo inciden en la dejación de armas o en el proceso de reincorporación de los militantes de las FarcEp a la vida civil, sino que implica el restablecimiento de los derechos de todas las personas que de alguna manera han sido víctimas de este conflicto armado interno que durante tanto tiempo ha lastimado a la ciudadanía.

En el Acuerdo Final se dedican, por lo menos 10 páginas a la cuestión de la norepetición del conflicto armado y podrían extraerse más de 30 citas en dónde se pone de manifiesto, de una manera explícita, el deseo de revertir los efectos del conflicto, sin contar con aquellas otras partes en donde se hace mención a ello de una manera

\footnotetext{
${ }^{7}$ Siempre se habla aquí de Acuerdo Final pero esta expresión debe entenderse como la sumatoria de todos los acuerdos alcanzados entre el Gobierno Nacional y las Farc-Ep. Estos se sintetizan en los siguientes títulos: 1) Reforma Rural Integral. 2) Participación política: Apertura democrática para construir la paz. 3) Cese al Fuego y de Hostilidades Bilateral y Definitivo y la Dejación de las Armas. Reincorporación de las Farc-Ep a la vida civil en lo económico, lo social y lo político de acuerdo con sus fines. Garantía de seguridad y lucha contra las organizaciones criminales responsables de homicidios y masacres o que atentan contra los defensores y defensoras de derechos humanos, movimientos sociales o movimientos políticos, incluyendo las organizaciones criminales que hayan sido denominadas como sucesoras del paramilitarismo y sus redes de apoyo, y a la persecución de las conductas criminales que amenacen la implementación de los acuerdos y la construcción de la paz. 4) Solución al problema de las drogas ilícitas. 5) Víctimas. 6) Mecanismos de implementación y verificación.
} 
tangencial. Esto quiere decir que, en verdad, esta cuestión aquí expresada no es del todo invisible a lo acordado entre las partes y que, antes bien, hace parte de uno de los alcances más importantes a los que les quieren apuntar muchos esfuerzos.

El reconocimiento de la paz como un derecho fundamental y, al mismo tiempo, como un propósito del Acuerdo Final conlleva a pensar en todas y cada una de las acciones que se podrían desarrollar para que el conflicto no vuelva a repetirse. Se asume un compromiso por parte de toda la ciudadanía para erradicar definitivamente la violencia de nuestra forma de pensamiento. Esto se argumenta más adelante cuando se menciona que la paz, como un derecho de cada uno de los ciudadanos es también una construcción que desde lo social debe impulsarse. Esto quiere decir que, sumado a los deseos de las Farc-Ep y del Gobierno Nacional, las acciones de todos deben contribuir a la consolidación de ese proceso de no-repetición.

La posibilidad de pensar en lo vivido en Colombia es único y no se debe dejar de lado la posibilidad para concebir de una forma distinta la nación, fortaleciendo siempre los deseos de progreso y de humanismo (Acuerdo Final, 2016):

El fin del conflicto constituye una oportunidad única para satisfacer uno de los mayores deseos de la sociedad colombiana y de las víctimas en particular: que se esclarezca y conozca la verdad de lo ocurrido en el conflicto. Colombia necesita saber qué pasó y qué no debe volver a suceder nunca más, para forjar un futuro de dignificación y de bienestar general y así contribuir a romper definitivamente los ciclos de violencia que han caracterizado la historia de Colombia (pp. 130-131 [p. 118]).

Aquí se evidencia otra de las cuestiones importantes en el proceso de pensamiento del proceso que afronta Colombia en este momento: la cuestión siempre discutible sobre la verdad de lo ocurrido. Es necesario conocer y comprender lo que en verdad ha sucedido en el pasado para poder comprometerse con la superación de ello: ello permitirá proyectar un camino distinto al recorrido. Hoy más que nunca se debe estudiar la historia, identidad, orígenes y errores para no repetirlos.

El desconocimiento de la historia de Colombia podría llevar a otra nueva manifestación de violencia interna que dure para siempre y que niegue la posibilidad de construir un destino diferente al vivido hasta ahora. Todos los esfuerzos deben estribar en eso: en conocer la historia sido para devenir algo distinto. Para ello se necesita del compromiso de toda la ciudadanía, pues de lo contrario cualquier intento por ser distintos estará condenado al fracaso.

Es necesario admitir que la no-repetición es un anhelo de la nación, con acciones claras y necesarias. El conocimiento de la verdad por parte de todos es urgente. Y por ello uno de los objetivos principales del Acuerdo Final es la consolidación de una Comisión para el Esclarecimiento de la Verdad, la convivencia y la no repetición que se encargará de buscar detalladamente las causas que han originado el conflicto armado en Colombia. Según el Acuerdo Final (2016):

[Esta comisión] será un órgano temporal y de carácter extrajudicial que busca conocer la verdad de lo ocurrido y contribuir al esclarecimiento de las violaciones e infracciones y ofrecer una explicación amplia a toda la sociedad de la complejidad del conflicto; promover el reconocimiento de las víctimas y de las responsabilidades de quienes participaron directa e indirectamente en el conflicto armado; y promover la convivencia en los territorios para garantizar la no-repetición (p. 129 [p. 117]). 
Y para cumplir con su objetivo tendrá:

Medidas de reparación para la construcción de la paz: Se trata de medidas que buscan asegurar la reparación integral para las víctimas, incluyendo los derechos para la restitución, la indemnización, la rehabilitación, la satisfacción y la no-repetición $[. .$.

Garantías de no-repetición: Las garantías de no-repetición son el resultado, por una parte, de la implementación coordinada de todas las anteriores medidas y mecanismos, así como en general de todos los puntos del Acuerdo Final; y por otro, de la implementación de medidas de no-repetición que se acuerden en el marco del punto 5 - «Fin del conflicto» (2016, pp. 129-130 [p. 117]).

La comisión tiene una importante tarea a la hora de esclarecer la verdad de lo ocurrido, pues de ello dependerá, en muy buen sentido, el hecho de superar las causas que han originado en conflicto armado interno en Colombia. En el apartado siguiente se muestran algunas de las referidas causas y se reflexiona acerca de la condición de dignificación planteada en el acuerdo. Como se manifiesta en las garantías de no-repetición esta es el resultado de todos los puntos del acuerdo, lo cual quiere decir que todas las acciones deben conducir a no-repetirlo, a eliminar cualquier manifestación de violencia del territorio e, incluso, del pensamiento de cada ciudadano.

Se intenta hacer una analogía con los alemanes al intentar superar la guerra con los Nazis. Ya Adorno (1998, p. 79) lo manifestó:

La exigencia de que Auschwitz no se repita es la primera de todas las que hay que plantear a la educación. Precede tan absolutamente a cualquier otra que no creo deber ni tener que fundamentarla. No puedo comprender por qué se le ha dedicado tan poca atención hasta el momento.
Ante la monstruosidad de lo ocurrido, fundamentarla tendría algo de monstruoso. Que se haya tomado tan poca consciencia de esta exigencia, y de los interrogantes y cuestiones que van con ella de la mano, muestra, no obstante, que lo monstruoso no haya calado lo bastante en las personas. Lo que no deja de ser un síntoma de la providencia de la posibilidad de repetición de lo ocurrido sí depende del estado de consciencia y de la inconsciencia de las personas. Cualquier posible debate sobre ideales educativos resulta vano e indiferente en comparación con esto: que Auschwitz no se repita. Fue la barbarie, contra lo que la educación entera procede.

$\mathrm{Y}$, en efecto, Colombia ha vivido su tragedia, una barbarie a lo largo de casi 60 años. ¿Cuántos colombianos han muerto a lo largo de estas décadas? ¿Cuántos más tendrán que morir en caso tal de desperdiciar esta oportunidad? Tal vez estas y otras tantas preguntas se hacía la población civil el 2 de octubre del 2016 cuando vieron que la campaña del no en el plebiscito por la paz ganaba sobre el sí. ¿Por qué? Pues muchos pensaron que en ese momento todo terminaría y que los militantes de las Farc-Ep regresarían a la selva a continuar con una lucha ya muy gastada y que nos dejaría ad portas de nuevas confrontaciones y de más muertes. Pero esto no ha sucedido y está la posibilidad latente de superar la barbarie que durante otros tiempos tanto ha afectado a la ciudadanía. Como parte de una misma nación es necesario consolidar el triunfo de la civilización.

Se reitera la necesidad descrita en cuanto al esclarecimiento de la verdad y que aparece en otro lado en el Acuerdo Final (2016):

Acuerdo 5. Acuerdo sobre las víctimas del conflicto: «sistema integral de Verdad, Justicia, Reparación y No-Repetición» incluyendo la Jurisdicción Especial para la Paz; compromiso sobre Derechos Humanos. 
[Como compromiso para llevar a cabo este acuerdo en sus mejores términos y resarcir a las víctimas del conflicto, intentando no volver a repetirlo, se firmó la «Declaración de principios» del 7 de junio del 2014, entre los que se incluyen los siguientes] $]^{8}$ :

El esclarecimiento de la verdad: Esclarecer lo sucedido a lo largo del conflicto, incluyendo sus múltiples causas, orígenes y sus efectos, es parte fundamental de la satisfacción de los derechos de las víctimas, y de la sociedad en general. La reconstrucción de la confianza depende del esclarecimiento pleno y del reconocimiento de la verdad.

La garantía de no repetición: El fin del conflicto y la implementación de las reformas que surjan del Acuerdo Final, constituyen la principal garantía de no-repetición y la forma de asegurar que no surjan nuevas generaciones de víctimas. Las medidas que se adopten tanto en el punto 5 como en los demás puntos de la Agenda deben apuntar a garantizar la no-repetición de manera que ningún colombiano vuelva a ser puesto en condición de víctima o en riesgo de serlo (pp. 124-125 [pp. 112-113]).

Como puede verse, el Acuerdo Final vuelve una y otra vez acerca de los mismos temas, pero siempre lo hace de una manera distinta. La preocupación por esclarecer la

\footnotetext{
${ }^{8}$ Esto que aparece entre corchetes es una paráfrasis introducida por el autor del presente artículo.

${ }^{9}$ Parece importante en este apartado mencionar el artículo titulado Memoria histórica razonada: Una propuesta incluyente para las víctimas del conflicto armado interno colombiano, cuya citación completa está en la bibliografía, pues aparte de hacer una propuesta que incluya a las víctimas, se realiza un énfasis fundamental en la cuestión de la Memoria Histórica, lo cual está a la base de nuestras consideraciones: en caso de desconocerse la verdad de lo ocurrido, las condiciones de posibilidad para que el conflicto vuelva a repetirse aumentan considerablemente. También recomendamos ver en este sentido otro texto intitulado Recordar y no Repetir: la potencialidad de la construcción de la Memoria Histórica en la contribución al fin del conflicto armado en Colombia (tesis de maestría). La cuestión es que debemos recordar y saber qué fue lo que sucedió en el conflicto interno colombiano y cuál fue su real origen para dar las garantías necesarias para no volver a repetirlo.
}

verdad de lo ocurrido está en la base de todos los acuerdos, pues en caso tal de no poder hacer esto no se podría llevar a cabo el proceso de superación del conflicto armado en Colombia.

\section{La no-repetición como superación de las} causas

Se han evidenciado dos de los aspectos fundamentales del Acuerdo Final: la idea de no repetición ${ }^{9}$ es una de las principales del texto y está intrínsecamente asociada a la del esclarecimiento de la verdad de lo ocurrido para identificar y corregir errores del pasado. Se intenta mostrar que para no repetir el conflicto armado se deben superar todas las causas que lo originaron. Es necesario superar las causas que lo originaron, para ello se debe comprender que tanto el Gobierno Nacional como las Farc-Ep, están de acuerdo con la transformación de las condiciones que han facilitado la persistencia de la violencia en el país:

Reparando que [considerando que $]^{10}$ a juicio del Gobierno Nacional las transformaciones que conlleva la implementación del presente Acuerdo deben contribuir a reversar los efectos del conflicto y a cambiar las condiciones que han facilitado la persistencia de la violencia en el territorio; y que a juicio de las Farc-Ep dichas transformaciones deben contribuir a solucionar las causas históricas del conflicto, como la cuestión no resuelta de la propiedad sobre la tierra y particularmente su concentración, la exclusión del campesinado y el atraso de las comunidades rurales, que afecta especialmente a las mujeres, niñas y niños (p. 3 [p. 2]).

\footnotetext{
${ }^{10}$ Este es uno de los cambios que hay en las dos versiones del Acuerdo Final. En la primera de ellas el párrafo comenzaba con lo que hay entre paréntesis, y en la segunda versión el párrafo comienza con la expresión que «reparando que». Ello no produce un cambio demasiado grande en la comprensión de lo que continúa.
} 
En el Acuerdo Final (2016) se hace explícito el daño y el dolor que han sufrido la mayoría de los habitantes del país en tantos años de conflicto armado interno:

El conflicto armado, que tiene múltiples causas, ha ocasionado un sufrimiento y un daño a la población sin igual en nuestra historia. Son millones los colombianos y colombianas víctimas de desplazamiento forzado, cientos de miles de muertos, decenas de miles de desaparecidos de toda índole y un amplio número de colectivos y poblaciones afectadas a lo largo y ancho del territorio, incluyendo comunidades campesinas, indígenas, afrocolombianas, negras, palenqueras, raizales, y rom, partidos políticos, movimientos sociales y sindicales, gremios económicos, entre otros. Sin olvidar otras formas menos visibles pero no menos dolorosas de victimización, como la violencia sexual, las afectaciones psicológicas, o la simple convivencia con el miedo (p. 126 [p. 114]).

Este es el momento histórico adecuado para proyectar una identidad nacional distinta y para fortalecer un proceso de postconflicto en donde las víctimas puedan curar sus heridas, cerrar la página y comenzar a escribir una nueva historia. Se hace necesario el esfuerzo de cada ciudadano, con la consciencia de cada uno para superar la cultura de violencia y aportar a la construcción de una nueva cultura de paz en donde cada uno tenga un espacio para hablar, participar, y que no sea estigmatizado por hacer oposición política como se mencionaba en alguna de las citas anteriores.

Es necesario notar aquí algo que es importante: una de las cuestiones a las cuales apunta el Acuerdo Final es que no haya una diferencia tan evidente o tan grande entre las comunidades rurales y las ciudades. El atraso del cual son víctimas los pobladores de las primeras es bastante profundo y el Acuerdo no lo desconoce. Por ello el primero de los acuerdos que se recogen allí es el de la Reforma Rural Integral (RRI) en dónde se plantea, no solo que los campesinos colombianos tengan más dinero, sino que tengan mejores recursos: de nada le vale a una población determinada tener mucho dinero pero no tener en qué gastarlo. Dicho de otro modo: la capacidad de adquisición debe ser congruente con los productos a adquirir. $\mathrm{Si}$ un campesino tiene demasiado dinero pero no puede comprar los servicios básicos para tener una vida digna aquél le será inservible. Por ello es importante que puedan disponibilidad económica pero también la posibilidad de inversión.

Por ello el Acuerdo Final (2016) hace énfasis en:

Que el desarrollo rural integral es determinante para impulsar la integración de las regiones y el desarrollo social y económico equitativo del país. La RRI debe lograr la gran transformación de la realidad rural colombiana, que integre las regiones, erradique la pobreza, promueva la igualdad, asegure el pleno disfrute de los derechos de la ciudadanía con un enfoque de género y como consecuencia garantizar la no-repetición del conflicto y la erradicación de la violencia ( $p$. 10 [p. 8]).

De esta manera se podría iniciar la erradicación de la pobreza: los campesinos deben tener las mismas oportunidades que las personas de zonas urbanas, con acceso a servicios públicos, un buen sistema de transporte y la posibilidad de aspirar a un mejor trabajo gracias a la educación que se recibe. De esta manera se cierran las brechas que han consolidado la permanencia de la violencia dentro del territorio nacional.

Como se refirió en una cita previa, han sido las víctimas de desplazamiento forzado, violaciones y otras conductas dañinas para la población. Una de las causas es la diferencia que hay entre lo rural y lo urbano 
y el Acuerdo Final hace referencia a ello. Otra de las causas potenciales de esto es la cuestión no resuelta de la propiedad sobre la tierra y el problema con las drogas ilícitas. Este último se reconoce dentro de las páginas del Acuerdo (2016):

Para contribuir con el propósito de sentar las bases para la construcción de una paz estable y duradera es necesario, entre otros, encontrar una solución definitiva al problema de las drogas ilícitas, incluyendo los cultivos de uso ilícito y la producción y comercialización de drogas ilícitas (p. 98 [p. 88]).

Sin embargo, aunque estas se convirtieron en un problema relacionado con la violencia, no fue siempre una de las causas que lo originaron aunque sí de las que lograron su permanencia en el territorio nacional. Al respecto el Acuerdo Final (2016) señala:

El conflicto interno en Colombia tiene una larga historia de varias décadas que antecede y tiene causas ajenas a la aparición de cultivos de uso ilícito de gran escala, y a la producción y comercialización de drogas ilícitas en el territorio (p. 98 [p. 88]).

Esto quiere decir que pueden existir dos tipos de causas a la hora de hablar del conflicto armado interno en Colombia: por un lado, están las que de alguna manera influenciaron el origen del fenómeno del paramilitarismo y por el otro las que conllevaron a que el conflicto armado se sostuviera a lo largo del tiempo. Las primeras permitieron la creación o establecimiento de las Farc-Ep, las segundas instauraron la posibilidad para su sostenimiento económico y para que este grupo pudiera mantener una guerra de más de medio siglo de duración. Las primeras estuvieron desde el principio del conflicto armado y las segundas fueron apareciendo a lo largo de los años como una consecuencia directa o indirecta del fenómeno del paramilitarismo.
El problema de las drogas apareció en algún punto de la historia de este conflicto como una manera de financiar las acciones que efectuaban los militantes de las Farc-Ep. Luego, ello se ha convertido en un problema o causa para el conflicto armado interno ya que gracias a este surgimiento se pudo mantener en el tiempo el conflicto. En cuanto tal, ambos tipos de causa deben superarse para negar las condiciones de posibilidad de que los hechos ocurridos no vuelvan a repetirse.

Finalmente y como conclusión de este segundo apartado se mencionar uno de los objetivos principales del Acuerdo Final referido a no volver a repetir el conflicto armado interno en Colombia. El punto 5.1.4 intitulado "Garantías de no-repetición» (Acuerdo Final, 2016, pp. 186-188 [165-167]) es una muestra clara de la preocupación porque los hechos ocurridos no vuelvan a repetirse. De igual forma el punto 5.1, en general, apunta a que no vuelva a repetirse el conflicto armado interno ${ }^{11}$.

\section{Un posible devenir: la construcción de un destino y una identidad}

Se reconoce que este momento histórico es único y posiblemente no vuelva a repetirse en un futuro. Por ello, es necesario asentar las bases y consolidar un postconflicto de tal manera que sean ciertas todas y cada una de las promesas que se encuentran en el Acuerdo Final. Pero ello será posible solamente si el conjunto completo de los colombianos está dispuesto a esforzarse. Si en este proceso se comienza a pensar que la tarea es solo del Gobierno Nacional

\footnotetext{
${ }^{11} \mathrm{El}$ punto gira en torno al Sistema Integral de Verdad, Justicia, Reparación y No-Repetición. Tomo apunta a la no repetición del conflicto armado interno en Colombia.
} 
y las Farc-Ep, y no de los ciudadanos en general, existirá una alta probabilidad de repetir la historia. Por ello uno de los objetivos principales en este proceso de superación de las causas que originaron el conflicto armado interno es la construcción y consolidación de la memoria histórica: saber lo que ha pasado para no volver a repetirlo. Por ello menciona el Acuerdo Final (2016):

En este nuevo escenario será posible aportar a la construcción y preservación de la memoria histórica y lograr un entendimiento amplio de las múltiples dimensiones del conflicto, incluyendo la dimensión histórica, de tal forma que no solo se satisfaga el derecho a la verdad sino que también se contribuya a sentar las bases de la convivencia, la reconciliación y la no-repetición. P. 130 - 131 [p. 118].

Es necesario identificar debilidades. Y lo primero que se debe hacer [con la ayuda de todos los ciudadanos y las ciudadanas] es la desarticulación de todos los grupos que intenten mediar con la violencia. La incorporación de los militantes de las FarcEp a la vida civil es una de las primeras metas a seguir: si han dejado las armas voluntariamente y quieren contribuir, como ciudadanos libres, a la consolidación de un nuevo destino para la sociedad, no se puede negarl la posibilidad de hacerlo. El compromiso de ellos de no volver a tomar las armas debe ser congruente con el deseo de los colombianos de tomar el camino de la paz.

Ante todo, se debe pensar que la manera más elocuente para la consolidación del proceso de paz es que haya sido una concertación y no una imposición, pues sería contradictorio todo discurso que hable de la paz y que haya aniquilado a su oponente. Por ello se menciona en el Acuerdo (2016):
Los Estados tienen el deber jurídico de atender los derechos de las víctimas y con la misma intensidad, la obligación de prevenir nuevos hechos de violencia y alcanzar la paz en un conflicto armado por los medios que estén a su alcance. La paz como producto de una negociación se ofrece como una alternativa moral y políticamente superior a la paz como producto del aniquilamiento del contrario. Por ello, el derecho internacional de los derechos humanos debe considerar a la paz como un derecho y al Estado como obligatorio a alcanzarlo (p. 143 [p.130]) ${ }^{12}$.

Toda concertación es superior al aniquilamiento del otro. Por ello es importante que este proceso de paz se haya llevado a cabo de una manera pacífica y no violenta. Es necesaria la defensa de la paz como un derecho de todos los colombianos y no una decisión de unos pocos; se trata de un proceso para beneficiar al gran colectivo de ciudadanos de esta nación y no los intereses de unos pocos.

Es necesario admitir la pertinencia de defender un Acuerdo Final de paz producto de una negociación y no de la aniquilación: cuando dos partes que han estado históricamente confrontadas por medio de la violencia se sientan a buscar salidas pacíficas al conflicto armado, pueden lograrse estrategias de superación en donde las vulneraciones y consecuencias sean positivas para la inmensa mayoría.

Se retoma el asunto de la reconstrucción de la memoria histórica y el desmantelamiento de los grupos paramilitares como primera acción para continuar un destino diferente sin volver a los errores del pasado.

\footnotetext{
12 Como pie de página aparece: "Voto recurrente, Corte Interamericana de Derechos Humanos, Caso Masacre de El Mozote y lugares Aledaños Vs El Salvador (CIDH, 2012)».
} 
Con la primera, como ya se ha dicho, se tendrá por sentado el conocimiento de la verdad de lo ocurrido para que las nuevas generaciones de colombianos sepan qué fue lo que sucedió, por qué sucedió y cómo fue que se superó una época tan compleja. Con lo segundo se podrá garantizar que los grupos de paramilitarismo herederos de las Farc-Ep no puedan fortalecer sus filas.

Resulta prioritario erradicar la violencia del territorio nacional. El Acuerdo Final (2016) plantea en este sentido:

Adicionalmente, el gobierno fortalecerá, concentrará y desplegará su máxima capacidad institucional para prevenir, desarticular y neutralizar, con un enfoque multidimensional cualquier posible fuente de violencia contra quienes ejercen la política y tomará todas las medidas necesarias para asegurar que no resurjan grupos de tipo paramilitar (p. 39 [p. 34]).

Los esfuerzos de todos los colombianos deben estar enfocados en el objetivo de la paz. Desde la educación comenzar a ganar más personas para formarlos integralmente en humanidades o en ingenierías para que la guerra no continúe reclutando jóvenes. El esfuerzo a realizar es profundo: demostrar que en verdad la formación vale la pena: que los jóvenes sean los que decidan aumentar los puestos en las universidades y no engrosar las filas de los ejércitos; que ellos reclamen su derecho a formarse y manifiesten su deseo de mejorar las condiciones en las cuales viven los colombianos. El fin último la identidad como nación podrá devenir en un país culto y educado.

La inversión que debe hacerse implica no solamente un mayor presupuesto para la educación, sino esto se pueda invertir de un mejor modo: de nada le serviría a una institución educativa tener un salón lleno de computadores si no tiene un capital humano que transmita el conocimiento. Es necesario una mayor inversión en educación: no solo en lo económico sino también en lo humano.

Con poner más atención en la educación, puede fortalecerse uno de los objetivos del Acuerdo Final: Para la consolidación de la paz se requiere así mismo la promoción de la convivencia, la tolerancia y no estigmatización, y, por esa vía, se promueva el respeto por quienes ejerzan la oposición política (2016, p. 35 [p. 36]). La promoción de una cultura del respeto y la tolerancia debe entenderse como una cultura de la paz ${ }^{12}$. Ello significa no solo enseñar a las personas a ser tolerantes sino a no estigmatizar al otro por sus condiciones sociales, económicas, religiosas e incluso sexuales, o por su ideología política. Así mismo, la educación debe permitir que las personas aprendan a resolver sus conflictos ${ }^{14}$ de una manera pacífica, para eliminar todas las consecuencias que ha traído la utilización de la violencia.

Es necesario retomar los dos elementos centrales que se han intentado desarrollar acá: la desarticulación de las bandas criminales y la cuestión de la verdad sobre lo sucedido. Es necesario cerrar las heridas que este conflicto armado interno haya causado en la población y, al mismo tiempo, para dejar grabado en la historia del país uno de los períodos más violentos para que las nuevas generaciones no vuelvan a cometer los mismos errores del pasado. Como primer objetivo para el postconflicto se debe plantear la reconstrucción de la memoria histórica.

\footnotetext{
${ }^{13}$ Debemos entender la cultura de la paz como lo opuesto a la cultura de la violencia y del silencio que gobierna en todos los países mientras estén sometidos a un conflicto armado interno como el de Colombia. La cultura de la paz es la preferencia de la educación, la cultura, el deporte y la resolución pacífica y dialogada de los conflictos inherentes a la naturaleza del hombre.

${ }^{14}$ Queremos llamar la atención con respecto a algo en este punto: para nosotros existen dos tipos de conflictos: aquellos que son impuestos por la guerra y utilizan la violencia como forma de reivindicación y aquellos otros conflictos que son propios de la naturaleza humana. Esta segunda noción es la que debe entenderse en este punto, aquella primera es la que se debe superar en el país con el proceso de paz.
} 
La otra cuestión de la desarticulación de los grupos al margen de la ley es importante para la negación de cualquier intento por repetir lo sucedido: que todas las posibilidades estén negadas para ello. El ideal, al iniciar un proceso de paz como el que se ha vivido en Colombia, es garantizar que en el futuro los hechos pasados no volverán a lastimar a nadie. Si esto no puede ser posible, cualquier idea de paz quedará sumida en el fracaso irremediablemente. En correspondencia con lo expuesto por Ferrel et al (2014), se trata de una sociedad integrada por personas satisfechas, con emociones positivas; ello traduce instituciones sólidas. Hacer todo lo posible por que los jóvenes elijan la educación, el arte, la cultura, la música como un medio de expresión y no las armas. Uno de los objetivos principales del Acuerdo Final (2016) para la no-repetición del conflicto armado interno es el desmantelamiento de las bandas armadas.

[De los principios orientadores del Acuerdo sobre garantías de seguridad y lucha contra las organizaciones criminales (punto 3.4) $]^{15}$.

Garantías de no repetición: El Estado adoptará las medidas para garantizar el esclarecimiento del fenómeno paramilitar, evitar su repetición y garantizar el desmantelamiento de las organizaciones criminales responsables de homicidios y masacres y violencia sistemática de género, o que atenten contra defensores de los derechos humanos, movimientos sociales o movimientos políticos, incluyendo las organizaciones criminales que hayan sido denominadas como sucesoras del paramilitarismo y sus redes de apoyo, la persecución de las conductas criminales que amenacen la implementación de los acuerdos y la construcción de la paz. (p. 80 [p. 81]).

${ }^{15}$ Lo que aparece entre corchetes es introducido por el autor para darle un poco de contexto a la cita. Ello no aparece en el Acuerdo Final
Así pues, el postconflicto es un evento histórico que afecta a todos. Una de las cuestiones que podría mejorar ese proceso de paz es el de pensar nuevamente el papel fundamental de la educación. Este es el momento oportuno para aportar un mayor capital a la educación: que no solo más estudiantes decidan ir a las universidades sino que el Gobierno Nacional decida aumentar su calidad.

Una educación de calidad y que al mismo tiempo sea accesible para más personas, es una oportunidad para cerrarle las puertas a las armas y que el campo y la ciudad no tengan tantas diferencias entre sí. El compromiso por la consolidación de este proceso de paz es la oportunidad, el momento clave, para fortalecer la educación en Colombia.

Una nueva identidad como nación supone pensar en un nuevo modelo de hombre, un nuevo ciudadano formado integralmente, consciente de su papel histórico, decida siempre el camino de la paz en vez del de la guerra. Debe involucre un mayor presupuesto en educación y mejorar su calidad: al mismo tiempo, garantizar que los docentes están más y mejor formados para cambiar la mentalidad de los jóvenes lo cual implicaría un mejor salario para ellos.

\section{Conclusiones}

Los actos de todos los colombianos deben estar enfocados a lo mismo: no repetir el conflicto armado interno. En cierto modo, esto es algo que vivió el país en el debate por el Plebiscito por la Paz cuando los opositores afirmaban que ellos también querían la paz pero no estaban conformes con algunos de los puntos del Acuerdo Final. Y pensar en algo distinto, en un rechazo completo de la paz para continuar sumidos en un conflicto armado interno por un tiempo indefinido, sería simplemente caer nuevamente en la repetición de los hechos ocurridos. 
Para contribuir a que ese pasado no se repita es necesario eliminar todas y cada una de las causas que originaron o hicieron que el conflicto armado interno persistiera en el territorio. El atraso en el campo debe superarse y el problema con las drogas ilícitas, mecanismo de financiamiento de la guerra, debe erradicarse. Las causas se eliminan si todos y cada uno de los colombianos y las colombianas se comprometen con el proceso que está viviendo en este momento la nación.

Es necesario cambiar la identidad como nación para eliminar cualquier rasgo de la violencia sufrida en tantos años y poder contribuir, en este sentido, a la no-repetición de los hechos ocurridos. Ello implicaría un cambio en formas de pensar y de ver el mundo. Este cambio es posible si se contribuye al mejoramiento de la educación: no solo aumentar el número de estudiantes que haya en los planteles educativos, sino aumentar el presupuesto para ella. Lo mismo se puede decir con el cuerpo de docentes: que estén más y mejor preparados para afrontar los retos que la educación planteará, y esto conlleva a mejores salarios para ellos, pues si están mejor formados para el cargo y son más competentes para desempeñarlo deben ganar más de lo que ganan ahora. Todo esto lleva a pensar que es posible un proceso de postconflicto, implicaría la superación de sus causas y la proyección de un futuro distinto, con participación de la ciudadanía, el Gobierno Nacional y los militantes de las Farc-Ep.

\section{REFERENCIAS}

Adorno, T. (1998). Educación para la emancipación. Madrid: Morata.

CIDH. (25 de octubre de 2012). Caso Masacres de El Mozote y Lugares Aledaños vs. El Salvador. [Serie C No. 252]. Recuperado de http://corteidh.or.cr/docs/ casos/articulos/seriec_252_esp.pdf
Ferrel, F., Thomas, J., Solano, A., Redondo, E. \& Ferrel, L. (2014). Bienestar psicológico en profesores de una Universidad privada del distrito de Santa Marta. Cultura Educación y Sociedad, 5(2). 61-76. Recuperado de https:// revistascientificas.cuc.edu.co/culturaeducacionysociedad/article/view/885

República de Colombia. Gobierno Nacional-Farc-Ep (2016). Acuerdo Final para la Terminación del Conflicto y la Construcción de una Paz Estable y duradera. (Versiones 24 de agosto y 24 de noviembre). [Online]. Recuperado de: www.altocomisionadoparalapaz.gov.co 